\title{
Research of influence and mechanism of combining exercise with diet control on a model of lipid metabolism rat induced by high fat diet
}

\author{
Chen Shaodong ", Zhou Haihong ${ }^{*}$, Lin Manting, Li Guohui, Zhao Zhengxiao and Zhang YM
}

\begin{abstract}
Objective: To investigate the influence and mechanism of combining exercise with diet control on a model of lipid metabolism rat induced by high fat diet.

Methods: Twenty-four male Wistar rats were randomly divided into 3 groups of 8: normal, model and intervention. The model group and intervention group were fed with high fat diet, while the normal group received basal feed. From day 1 , the intervention group was randomly given interventions such as swimming exercise and dietary restriction. The interventions duration were 28 days. At the end of the experiment, the levels of rats' body weight and liver weight were detected, the serum levels of total cholesterol (TC), high density lipoprotein cholesterol (HDL-C), low density lipoprotein cholesterol (LDL-C) and hepatic triglyceride content (TG) were detected by using biochemical assay, serum level of gastrin (GAS), motilin (MTL) were assayed by the enzyme linked immunosorbent assay (ELISA).

Results: Compared with the level of body weight and liver weight in the normal rats, body weight and liver weight in the rat of the model group were significantly increase $(P<0.05$ or $P<0.01)$. Plasma concentrations of $T C$, $L D L-C$ and hepatic TG in the model group were significantly increased compared with those in the normal group $(\mathrm{P}<0.05$ or $\mathrm{P}<0.01)$. The contents of GAS, MTL, HDL-C in the model rats'plasma were significantly reduced compared with those of the normal group $(P<0.05$ or $P<0.01)$. Compared with those in the model group, rats' body weight, liver weight, serum TC, LDL-C, and TG content of liver in the intervention group decreased significantly $(P<0.05$ or $P<0.01)$. Meanwhile, serum content of GAS, MTL, HDL-C were significantly improved in the intervention rats compared to the model group.
\end{abstract}

Conclusion: The action of combining exercise with diet control for lipid metabolism disorder might be related to regulation of GAS, MTL and other gastrointestinal hormones.

Keywords: Lipid metabolism disorder, Rat, Intervention, Gastrointestinal hormones

\section{Introduction}

Lipid metabolism disorder refers to a disruption of lipid metabolism with exceeding serum levels of total cholesterol (TC), triglyceride (TG), low density lipoprotein cholesterol (LDL-C), and/or lower level of high density lipoprotein cholesterol (HDL-C). Serum levels of lipids and lipoprotein lipids are among the most potent and best substantiated risk factors for atherosclerotic diseases, particularly coronary heart disease (CHD) $[1,2]$. Therefore, it is very important to strengthen the

* Correspondence: adong@xmu.edu.cn; hhzhou@xmu.edu.cn prevention and cure of lipid metabolism disorder. In able-bodied individuals, exercise programs are important in the prevention and control of lipid metabolism disorders. Systematic reviews have also identified strong evidence that exercise and dietary restriction can improve lipoprotein levels in overweight able-bodied individuals [3]. But mechanism of the intervention of combining exercise with diet control remains to be further defined. It is now recognized that lipid metabolism is regulated by the reciprocal actions of a group of anorexigenic peptides, which include leptin, insulin, cholecystokinin, peptide YY and glucagon-like peptide.

\section{C) Biomed Central}

(c) 2013 Shaodong et al.; licensee BioMed Central Ltd. This is an Open Access article distributed under the terms of the Creative Commons Attribution License (http://creativecommons.org/licenses/by/2.0), which permits unrestricted use, distribution, and reproduction in any medium, provided the original work is properly cited. 
The majority of these hormones are secreted by endocrine cells scattered throughout the gastrointestinal tract [4]. While many studies reveal that gastrointestinal hormones play a notable role in regulating energy intake [5,6]. In this paper, we will focus on the underlying mechanisms of the intervention of combining exercise with diet control on the lipid metabolism disorder.

\section{Methods \\ Reagents}

TG kit, TC kit, HDL-C kit and LDL-C kit were purchased from Nanjing Jiancheng Biotechnology Co., Ltd. (Nanjing, China). Gastrin(GAS) ELISA kit and motilin (MTL) ELISA kit were obtained from R\&D Co., Ltd.(USA).

High fat diet include $83.25 \%$ basal feed, $10 \%$ lard, 1.5\% Clesterol, 0.2\% NaTDC, 5\% Sugar and 0.05\% Propylthiouracil.

\section{Animal grouping}

Twenty-four male Wistar rats $(175 \pm 7 \mathrm{~g})$ provided by the Experimental Animal Center of Medical College of Xiamen University (Xiamen, China), Animal License Key:SCXK (Hu) 2007_0005) were used. The use of animals in this study was approved by the Ethics Committee of Xiamen University (protocol XMULAC20120020).

Rats were randomly divided into 3 groups of 8: normal, model and intervention. From the first day of experiment, animals in the normal group were given basal feed, while rats in the model group and intervention group were fed with high faty diet for 28 days. In the meantime, rats in the intervention group were given different interventions randomly such as swimming exercise and dietary restrictions everyday. Time of swimming exercise was 30 minutes, deepth of water was 55 centimeter and temperature of water was $25^{\circ} \mathrm{C}$. The amount of food for rats in the intervention group was restricted to $50 \%$ of the model group.

\section{Determination of level of body weight and liver weight}

Rats were weighted at the day 1 and day 28 of the experiment. At the day 28 , rats were injected with $10 \%$ chloral hydrate $(0.36 \mathrm{~mL} / 100 \mathrm{~g}$ body weight intraperitoneal injection). After the injection of anesthesia, rats underwent laparotomy. Liver in rats were weighted.

\section{Determination of serum TC, LDL-C and HDL-C Content}

Blood $(5 \mathrm{ml})$ was draw from the abdominal aortic into a tube, and was centrifuged at $10,000 \times \mathrm{g}$ for $10 \mathrm{~min}$ at $4^{\circ} \mathrm{C}$. The supernatant was then used to measure the content of TC, LDL-C and HDL-C in serum by atomic absorption spectroscopy.
Determination of the concentration of Plasma GAS, MTL Plasma stored in $-20^{\circ} \mathrm{C}$ at room temperature was allowed to thaw. It was then centrifuged at at $10,000 \times \mathrm{g}$ for $10 \mathrm{~min}$ at $4^{\circ} \mathrm{C}$. The supernatant was removed, and the content of GAS and MTL plasma was measured using the enzyme linked immunosorbent assay (ELISA).

\section{Determination of hepatic TG content}

For the measurement of TG in liver tissue, frozen liver tissues were homogenized in PBS, and methanol was added to the lysate. The lipids were extracted by the method of Bligh and Dyer [7], and triglyceride content was measured using a TG kit.

\section{Statistical analysis}

Data are expressed as mean \pm standard deviation. Data were analyzed using Statistical Package for Social Sciences v11.0 software (SPSS, Chicago, IL, USA). One way analysis of variance (ANOVA) followed by q test were used to determine significant differences among the 3 groups. $\mathrm{P}<0.05$ was considered significant.

\section{Results}

\section{Comparison of levels of body weight and liver weight}

On day 1 of the experiment, body weight in each group were not significantly different $(\mathrm{P}>0.05)$. On day 28 , compared with the normal group, the body weight and liver weight of the model group were significantly increased $(\mathrm{P}<0.05, \mathrm{P}<0.01)$. This finding suggested that raising the rats in high fat diet could successfully establish a model of lipid metabolism disorder. Compared with the model group, body weight and liver weight of the intervention group had remarkably decreased $(\mathrm{P}<0.05, \mathrm{P}<0.01)$. This finding suggested that intervention had effects in improving disturbance of lipid metabolism (Table 1).

\section{Comparison of serum levels of TC, LDL-C,HDL-C and hepatic level of TG}

Compared with the content of TC, LDL-C and HDL-C in the serum of rats of the normal group $(4.00 \pm 0.73$ $\mathrm{mmol} / \mathrm{L}, 2.28 \pm 0.89 \mathrm{mmol} / \mathrm{L}$ and $0.57 \pm 0.14 \mathrm{mmol} / \mathrm{L}$ respectively), serum TC, LDL-C levels in model rats increased significantly to $5.98 \pm 1.07 \mathrm{mmol} / \mathrm{L}, 4.03 \pm 0.96$ $\mathrm{mmol} / \mathrm{L}$ and the HDL-C content was significantly

Table 1 Comparison of body weight and liver weight $(\bar{x} \pm s)$

\begin{tabular}{llll}
\hline Group & $\mathbf{n}$ & Body weight $(\mathbf{g})$ & Liver weight(g) \\
\hline normal & 8 & $250.6 \pm 40.2$ & $8.97 \pm 0.24$ \\
model & 8 & $314.6 \pm 39.3^{*}$ & $13.33 \pm 0.74^{* *}$ \\
intervention & 8 & $265.8 \pm 20.6^{\#}$ & $10.93 \pm 0.5^{\# \#}$ \\
\hline
\end{tabular}

Notes: ${ }^{*} \mathrm{P}<0.05,{ }^{* *} \mathrm{P}<0.01$, compared with the normal group;

${ }^{\#} \mathrm{P}<0.05,{ }^{\# \#} \mathrm{P}<0.01$, compared with the model group. 
reduced to $0.24 \pm 0.03 \mathrm{mmol} / \mathrm{L}(\mathrm{P}<0.05, \mathrm{P}<0.01)$. In the meantime, compared with the level of hepatic TG in the rats of the normal group $(1.42 \pm 0.51 \mathrm{mmol} / \mathrm{L})$, the content of hepatic TG in the rats of the model group was significantly increased to $3.31 \pm 0.74 \mathrm{mmol} / \mathrm{L} \quad(\mathrm{P}<0.01)$. This finding suggested that lipid metabolism disorder in a model of rats.

Compared with the model group, the intervention group had a regulatory role in lipid metabolism. Serum levels of TC, LDL-C and hepatic TG content in the rats of the intervention group were lower $(4.40 \pm 0.64 \mathrm{mmol} /$ $\mathrm{L}, 2.97 \pm 0.68 \mathrm{mmol} / \mathrm{L}$ and $2.44 \pm 0.19 \mathrm{mmol} / \mathrm{L}$ ), whereas HDL-C content increased significantly to $0.33 \pm 0.06$ $\mathrm{mmol} / \mathrm{L}(\mathrm{P}<0.05, \mathrm{P}<0.01$, Table 2$)$.

\section{Comparison of the concentration of plasma GAS, MTL}

The plasma concentrations of GAS and MTL of rats in the model group were $0.183 \pm 0.006 \mathrm{ng} / \mathrm{mL}$ and 0.224 $\pm 0.022 \mathrm{ng} / \mathrm{mL}$, respectively. Compared with the respective values in the normal group, $0.209 \pm 0.010 \mathrm{ng} / \mathrm{mL}$ and $0.279 \pm 0.033 \mathrm{ng} / \mathrm{mL}$, they were significantly decreased $(\mathrm{P}<0.05)$. These findings suggested there is a change in gastrointestinal hormones for lipid metabolism disorder.

The plasma concentrations of GAS and MTL of the intervention group was significantly higher than those in the model group $(0.206 \pm 0.008 \mathrm{ng} / \mathrm{mL}$ and $0.260 \pm 0.026 \mathrm{ng} / \mathrm{mL}$, respectively, $\mathrm{P}<0.05$, Table 3 ). This finding suggested that intervention improved gastrointestinal hormones dysfunction.

\section{Discuss}

Modern day lifestyle and diet dramatically increase the threat of lipid metabolism disorder. This metabolic disorders has been consistently linked to the imbalance between energy consumption and expenditure. Growing evidence suggests that faulty regulation of lipid metabolism promotes metabolic diseases [8]. As we know, the exercise and diet control are the best way to control the lipid metabolism disorder.

In this study, the model of lipid metabolism disorder was built successfully induced by high fat diet rats. The level of body weight, liver weight, plasma concentrations of TC, LDL-C and hepatic TG were significantly increased,while plasma concentrations of HDL-C was
Table 3 Comparison of the concentration of plasma GAS, $\operatorname{MTL}(\bar{x} \pm s)$

\begin{tabular}{llll}
\hline Group & $\mathbf{n}$ & $\mathbf{G A S}(\mathbf{n g} / \mathbf{m L})$ & $\mathbf{M T L}(\mathbf{n g} / \mathbf{m L})$ \\
\hline normal & 8 & $0.209 \pm 0.010$ & $0.279 \pm 0.033$ \\
model & 8 & $0.183 \pm 0.006^{*}$ & $0.224 \pm 0.022^{*}$ \\
intervention & 8 & $0.206 \pm 0.008^{\#}$ & $0.260 \pm 0.026^{\#}$
\end{tabular}

Notes: ${ }^{*} \mathrm{P}<0.05$, compared with the normal group;

${ }^{\#} \mathrm{P}<0.05$, compared with the model group.

significantly reduced. Combining exercise with diety restriction has function to improve the above index. It is hypothesized by Richter EA that exercise-induced increases in AMP-activated protein kinase (AMPK), an enzyme that, among many other functions, stimulates glucose uptake and fatty acid oxidation while decreasing lipid synthesis, may explain the observed associations between exercise and reduced metabolic disease [9-12].

In recently, the role of gastrointestinal hormones play in the regulation of lipid metabolism become more and more important. Gastrointestinal hormones has function to optimize the process of digestion and absorption of nutrients by the gut [13]. By altering the rate at which nutrients are delivered to compartments of the alimentary canal, the control of food intake arguably constitutes another point at which intervention may promote efficient digestion and nutrient uptake [14].

Motilin is one of gastrointestinal hormones, a 22amino-acid peptide synthesized from endocrine cells of the duodeno-jejunal mucosa [15], interacts directly with its receptor, induces smooth muscle contraction and improves peristalsis in the small intestine $[16,17]$. Motilin regulates the interdigestive migrating contractions (IMC), the fasted motor pattern in the gastrointestinal (GI) tract [18]. Motilin plasma levels increase cyclically every 90-120 minutes during the interdigestive fasting period, and this cyclical release of motilin disappears after ingestion of a meal. These cyclical peaks of plasma motilin are synchronized to strong peristaltic contractions initiated from the stomach and migrating to the duodenum and small intestine. This pattern of migrating waves is known as the phase III contraction of IMC. In the present study, the serum motilin level was significantly lower in model rats than in normal rats and significantly higher after intervention with combining

Table 2 Comparison of serum levels of TC, LDL-C,HDL-C and hepatic level of TG( $\bar{x} \pm s)$

\begin{tabular}{llllll}
\hline Group & $\mathbf{n}$ & Hepatic TG(mmol/L) & Serum TC(mmol/L) & Serum LDL-C(mmol/L) & Serum HDL-C(mmol/L) \\
\hline normal & 8 & $1.42 \pm 0.51$ & $4.00 \pm 0.73$ & $2.28 \pm 0.89$ & $0.57 \pm 0.14$ \\
model & 8 & $3.31 \pm 0.74^{* *}$ & $5.98 \pm 1.07^{* *}$ & $4.03 \pm 0.96^{*}$ & $0.24 \pm 0.03^{* *}$ \\
intervention & 8 & $2.44 \pm 0.19^{\#}$ & $4.40 \pm 0.64^{\# \#}$ & $2.97 \pm 0.68^{\#}$ & $0.33 \pm 0.06^{\#}$ \\
\hline
\end{tabular}


exercise with diet control. It is reported in the study of Miegueu P, motilin may directly influence adipocyte functions by controlling energy storage [19].

Gastrin was subsequently shown to be secreted from neuroendocrine $G$ cells which are principally located in the antrum of the stomach. The gastrin gene is located on the long arm of chromosome 17 and encodes a 101 amino acid polypeptide, preprogastrin. This gene product is subjected to a series of post translational modifications which result in the synthesis of a number of biologically active peptides [20]. Gastrin normally regulates gastric acid secretion by stimulating the proliferation of enterochromaffin-like cells and the release of histamine $[21,22]$. The researches about effect of gastrin on sphincter od Oddi are rare. But in the research of Saqui-Salces M, results show that components of food (fat) are sensed by antral cilia on endocrine cells, which modulates gastrin secretion and gastric acidity [23]. In our study, the content of serum GAS in rats of the model group decreased significally compared with those of normal group, while significantly increase after intervention.

In the research, it showed us gastrointestinal hormones play a critical role in the lipid metabolism disorder and intervention has function to improve the level of serum of GAS and MTL in the model rats.

\section{Competing interests}

The authors declare that they have no competing interests.

\section{Authors' contributions}

$\mathrm{CS}$ and $\mathrm{ZH}$ carried out the animal experiment studies and drafted the manuscript. LM, LG, ZZ and ZYM participated in the molding process and carried out the detection index testing. All authors read and approved the final manuscript.

\section{Acknowledgement}

This research was funded by Xiamen Science and Technology Key Program Grant (No.3502Z20100006)

Received: 16 January 2013 Accepted: 1 February 2013

Published: 20 February 2013

\section{References}

1. Samad F, Badeanlou L, Shah C, Yang G: Adipose tissue and ceramide biosynthesis in the pathogenesis of obesity. Adv Exp Med Biol 2011, 721:67-86.

2. Zhang F, Du G: Dysregulated lipid metabolism in cancer. World J Biol Chem. 2012, 3(8):167-174.

3. Shaw K, Gennat H, O'Rourke P, Del Mar C: Exercise for overweight or obesity. Cochrane Database Syst Rev 2006, 4:CD003817. PMID:17054187.

4. Cummings $D E$, Overduin J: Gastrointestinal regulation of food intake. J Clin Invest 2007, 117(1):13-23.

5. Overduin J, Schoterman MH, Calame W, Schonewille AJ, Ten Bruggencate SJ: Dietary galacto-oligosaccharides and calcium: effects on energy intake, fat-pad weight and satiety-related, gastrointestinal hormones in rats. Br J Nutr 2012, 31:1-11.

6. Koch M, Horvath TL: Reward aspects of gastrointestinal hormones mediated by brain g protein-coupled receptors. Biol Psychiatry 2012, 72(5): 340-342.

7. Bligh EG, Dyer WJ: A rapid method of total lipid extraction and purification. Can J Biochem Physiol 1959, 37(8):911-917.
8. Pathare PP, Lin A, Bornfeldt KE, Taubert S, Van Gilst MR: Coordinate. Regulation of Lipid Metabolism by Novel Nuclear Receptor Partnerships. PLOS Genet 2012, 8(4):e1002645. PMCID: PMC3325191.

9. Richter EA, Ruderman NB: AMPK and the biochemistry of exercise: implications for human health and disease. Biochem J 2009, 418(2):261-275

10. Haldar SM, Jeyaraj D, Anand P, Zhu H, Lu Y, Prosdocimo DA, Eapen B, Kawanami D, Okutsu M, Brotto L, Fujioka H, Kerner J, Rosca MG, McGuinness OP, Snow RJ, Russell AP, Gerber AN, Bai X, Yan Z, Nosek TM, Brotto M, Hoppel $C L$, Jain MK: Kruppel-like factor 15 regulates skeletal muscle lipid flux and exercise adaptation. Proc Natl Acad Sci USA 2012, 109(17):6739-6744.

11. Yi CX, Al-Massadi O, Donelan E, Lehti M, Weber J, Ress C, Trivedi C, Müller TD, Woods SC, Hofmann SM: Exercise protects against high-fat dietinduced hypothalamic inflammation. Physiol Behav 2012, 106(4):485-490.

12. Richter EA, Ruderman NB: AMPK and the biochemistry of exercise: Implications for human health and disease. Biochem J 2009, 418(2):261-275. PMCID: PMC2779044.

13. Blundell JE, Caudwell P, Gibbons C, Hopkins M, Naslund E, King N, Finlayson $\mathrm{G}$ : Role of resting metabolic rate and energy expenditure in hunger and appetite control: a new formulation. Dis Model Mech 2012, 5(5):608-613.

14. Bascietto C, Giannini C, D'Adamo E, de Giorgis T, Chiarelli F, Mohn A: Implications of gastrointestinal hormones in the pathogenesis of obesity in prepubertal children. J Pediatr Endocrinol Metab 2012, 25(3-4):255-260.

15. Poitras P, Peeters TL: Motilin. Curr Opin Endocrinol Diabetes Obes 2008, 15(1): 54-57.

16. Nunoi H, Matsuura B, Utsunomiya S, Ueda T, Miyake T, Furukawa S, Kumagi T, Ikeda Y, Abe M, Hiasa Y, Onji M: A relationship between motilin and growth hormone secretagogue receptors. Regul Pept 2012, 176(1-3):2835 .

17. Ceddia R: Motilin beyond gut motility: a novel role in the regulation of adipose tissue metabolism. Am J Physiol Endocrinol Metab 2011, 301(5): 756-757.

18. Itoh Z: Motilin and clinical application. Peptides 1997, 18(4):593-608.

19. Miegueu P, Cianflone K, Richard D, St-Pierre DH: Motilin stimulates preadipocyte proliferation and differentiation and adipocyte lipid storage. Am J Physiol Endocrinol Metab 2011, 301(5):758-766.

20. Burkitt MD, Varro A, Pritchard DM: Importance of gastrin in the pathogenesis and treatment of gastric tumors. World J Gastroenterol 2009, 15(1):1-16. PMCID: PMC2653300.

21. Fourmy D, Gigoux V, Reubi JC: Gastrin in gastrointestinal diseases. Gastroenterology 2011, 141(3):814-818

22. Mazaki-Tovi M, Segev G, Yas-Natan E, Lavy E: Serum gastrin concentrations in dogs with liver disorders. Vet Rec 2012, 171(1):19.

23. Saqui-Salces M, Dowdle WE, Reiter JF, Merchant JL: A high-fat diet regulates gastrin and acid secretion through primary cilia. FASEB J 2012, 26(8):3127-3139.

doi:10.1186/1476-511X-12-2

Cite this article as: Shaodong et al:: Research of influence and mechanism of combining exercise with diet control on a model of lipid metabolism rat induced by high fat diet. Lipids in Health and Disease 2013 12:21

\section{Submit your next manuscript to BioMed Central and take full advantage of:}

- Convenient online submission

- Thorough peer review

- No space constraints or color figure charges

- Immediate publication on acceptance

- Inclusion in PubMed, CAS, Scopus and Google Scholar

- Research which is freely available for redistribution 